\title{
Experimental Hypothalamic or Genetic Obesity in the Non-Insulin-Dependent Diabetic Rat
}

\author{
B. Portha ${ }^{1}$, R. Goursot ${ }^{1}$, M. H. Giroix ${ }^{1}$, S. Nicolaïdis ${ }^{2}$ and L. Picon ${ }^{1}$ \\ ${ }^{1}$ Laboratory of Developmental Physiology and Associate Laboratory of the CNRS No. 307, University of Paris 7 and \\ ${ }^{2}$ Laboratory of Regulative Neurobiology, CNRS ER 218, College of France, Paris, France
}

\begin{abstract}
Summary. Non-insulin-dependent diabetes was obtained in adult rats by neonatal administration of streptozotocin $(100 \mathrm{mg} / \mathrm{kg})$. Obesity was obtained in the same animals either by a ventromedial hypothalamic lesion in adult non-insulindependent diabetic Wistar rats, or by using genetically obese Zucker rats. In diabetic rats, weight gain was similar to that in non-diabetic rats, whether hyperphagia was due to a ventromedial hypothalamic lesion or to a genetic factor. Glucose-induced insulin release in vivo was increased in obese diabetic rats compared with non-diabetic rats. Despite this enhanced insulin secretion, both diabetic 'fatty' Zucker rats and diabetic rats with hypothalamic obesity showed a deterioration of glu-
\end{abstract}

cose tolerance. Moreover, about one-third developed overt diabetes with permanent or transient glycosuria. We conclude that when insulin-deficient rats are made hyperphagic, they are able to increase their insulin secretion and become obese. In some of these animals the occurrence of obesity aggravates the diabetes. The obese diabetic rat appears to be a suitable laboratory model for the study of the relationship between obesity and diabetes.

Key words: Non-insulin-dependent diabetes, obesity, ventromedial hypothalamic lesion, fatty Zucker rat, streptozotocin, insulin secretion, glucose tolerance.
Some forms of human non-insulin-dependent diabetes are clearly related to over-nutrition. There are populations in which the availability of excess calories increases the prevalence of diabetes [1]. In the genetically diabetic Chinese hamster there is some evidence that hyperphagia and obesity during the prediabetic stage may contribute to the development of overt diabetes $[6,7]$. However, in this animal model, it is not easy to evaluate the effect of obesity on diabetes since these two pathological states are always associated.

In experimental diabetes induced in adult rats by pancreatectomy, alloxan or streptozotocin (STZ), the modulatory effect of obesity upon the evolution of diabetes could not hitherto be studied, since obesity was never obtained $[5,15,16]$.

We have recently developed an experimental model in which non-insulin-dependent diabetes is obtained in the rat by a neonatal STZ injection. The adult animal is characterized by a chronic and stable state of low insulin response to glucose and amino-acids, a slight but consistent elevation of basal plasma glucose values and a slightly impaired glucose tolerance [10]. We have shown that acute diabetes in the newborn rat (unlike the adult rat) is followed by partial spontaneous recovery, and that complete recovery from neonatal diabetes is never achieved even in old rats [10]. We have used this model of non-insulin-dependent diabetes to answer two questions: (1) can obesity be obtained in these animals and (2) if so, does obesity modify the course of diabetes?

Two experimental designs were used to associate obesity with experimental diabetes in the adult rat. One used an electrolytic lesion of the ventromedial hypothalamus in adult Wistar rats with non-insulin-dependent diabetes. The other used genetically obese rats from the Zucker $f a / f a$ strain made diabetic by a neonatal injection of STZ.

\section{Material and Methods}

\section{Animals}

Two different strains of rat were used: (1) albino Wistar rats, bred in the laboratory and fed ad libitum with pelleted chow (UAR, Villemoisson s/Orge, France - carbohydrate $47 \%$, protein $24 \%$, fat $8 \%$, minerals $6 \%$, cellulose $3 \%$, water $12 \%$ ) and (2) Zucker rats bred in the laboratory under the same conditions. In order to increase the fertility of the obese male Zucker rats, these animals were treated with testosterone $20 \mathrm{mg}$ subcutaneously once every 3 days from 3 to 6 months [8] and had limited access to food, since excessive obesity favours reproductive failure [17]. Female Wistar or heterozygous ( $\mathrm{Fa} / \mathrm{fa}$ ) lean fe- 

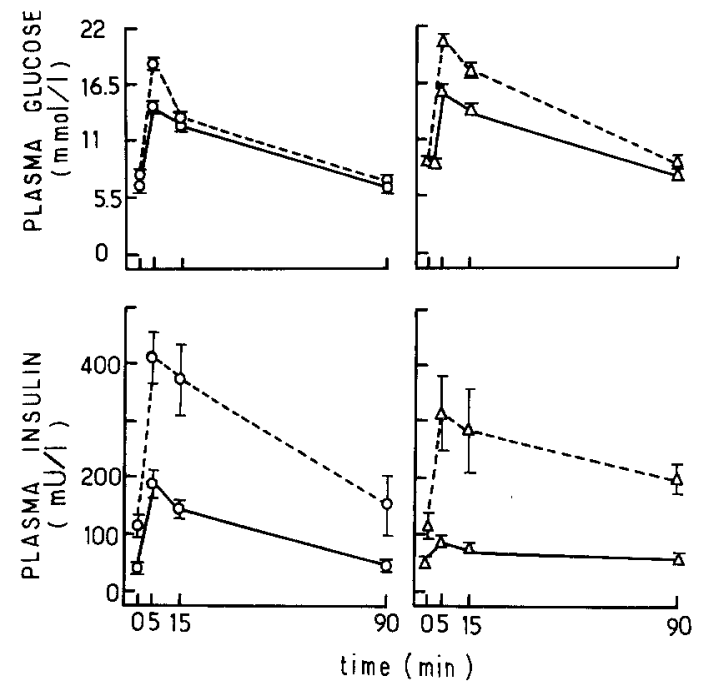

Fig.1. Effect of induced obesity on glucose tolerance and plasma insulin response to glucose $(2.8 \mathrm{mmol} / \mathrm{kg}$, IV) in control $(\mathrm{O}-\mathrm{O})$ and in diabetic $(\Delta-\Delta)$ female rats. Non-insulin-dependent diabetes was induced in the adult rats by a neonatal STZ $(100 \mathrm{mg} / \mathrm{kg})$ injection. Measurements were made at $5 \pm 1$ months just before $\mathrm{VMH}$ lesion (-) and 2 months after the lesion (----). Each point is mean \pm SEM of 13-21 observations in each group

male Zucker rats were caged with either a male Wistar or a homozygous $f a / f a$ male Zucker rat respectively and pregnancy was detected by abdominal palpation.

On the day of birth, newborn rats received streptozotocin $(100$ $\mu \mathrm{g} / \mathrm{g})$ in $25 \mu \mathrm{l}$ of citrate buffer $(0.05 \mathrm{~mol} / 1, \mathrm{pH} 4.5)$, through the saphenous vein by transcutaneous puncture [9]. Litters were limited to eight. Four days after birth, all neonates exhibited glycosuria reaching Clinistix value 3+ (Ames Division, Miles Laboratories, Paris, France). In the Wistar rats, spontaneous evolution of neonatal diabetes led to a non-insulin-dependent diabetic state in the adult which was stable and chronic as described previously [10]. In control litters, newborn rats received citrate buffer only. In the Zucker newborn rats evolution of daily glycosuria, after STZ injection, was similar to that observed in the Wistar neonates [9]. All animals were weaned 21 days after birth. Both diabetic and control female Wistar rats had ventromedial hypothalamic (VMH) lesions made under pentobarbital anaesthesia ( $4 \mathrm{mg} / 100 \mathrm{~g}$ body weight, IP) at the age of $5 \pm 1$ month, with the teeth bar $2.5 \mathrm{~mm}$ below the ear bars. The stereotactic coordinates used were: $5.9 \mathrm{~mm}$ anterior to the interaural line, $0.6 \mathrm{~mm}$ lateral to the midline and $9 \mathrm{~mm}$ below the surface of the dura mater.

Electrolytic lesions were obtained by passing $2 \mathrm{~mA}$ of anodal direct current for $20 \mathrm{~s}$. On completion of the experiments, correct lesion placement was confirmed histologically.

\section{Samples}

In Wistar control and diabetic female rats glucose tolerance was tested just before and 2 months after the VMH lesion. Rapid intravenous glucose tolerance tests $(2.8 \mathrm{mmol}$ glucose $/ \mathrm{kg}$ body weight) were performed in the fed state under pentobarbital anaesthesia $(4 \mathrm{mg} / 100 \mathrm{~g}$ body weight, IP). Blood was sampled from the tail vein and immediately centrifuged at $4{ }^{\circ} \mathrm{C}$; plasma was stored at $-20^{\circ} \mathrm{C}$ until assayed.

In lean and obese Zucker females, whether STZ-treated or not glucose tolerance was determined at 3 months. After the last glucose tolerance test each animal was killed; the pancreas was dissected, weighed and homogenized by ultrasonic disintegration at $4{ }^{\circ} \mathrm{C}$ (Sonifier Branson B12 Heat Systems-Ultrasonics, Plainview, Connecticut, USA) in a acid-alcohol solution ( $75 \%$ ethanol, $1.5 \% \mathrm{v} / \mathrm{v}, 12 \mathrm{~mol} / 1$ $\mathrm{HCl}, 23.5 \%$ distilled water). After one night at $-20^{\circ} \mathrm{C}$, the extracts were centrifuged and the supernatants kept at $-20^{\circ} \mathrm{C}$ until assayed.
Assays

Plasma glucose was determined using a glucose analyser (Beckman, Palo Alto, California, USA). Plasma immunoreactive insulin was estimated using purified rat insulin as a standard ( $R$ 171, Novo, Copenhagen, Denmark), antibody to a mixture of porcine + bovine insulin, and porcine monoiodinated ${ }^{125} \mathrm{I}$-insulin [4]. This method allows the determination of $6 \mathrm{mU} / 1(0.25 \mathrm{ng} / \mathrm{ml})$ with a coefficient of variation within and between assays of $10 \%$. Silicate was used to separate free from bound hormone [12]. The pancreatic insulin was assayed similarly.

\section{Calculations}

Insulin response during the glucose tolerance test was calculated as the insulinogenic index [13], which is the ratio of incremental plasma insulin values $\left(\mathrm{mU} \cdot \mathrm{min} \cdot \mathrm{1}^{-1}\right.$ ), integrated over the 90 -min period following the injection of glucose, to the corresponding incremental integrated plasma glucose values $\left(\mathrm{mmol} \cdot \mathrm{min} \cdot 1^{-1}\right)$.

The results are given as mean \pm SEM. For statistical analysis, Student's unpaired t-test was used.

\section{Results}

Ventromedial Hypothalamic Lesion in Wistar Rats with Non-Insulin-Dependent Diabetes

Effect on the development of obesity and on basal plasma glucose and insulin levels: a comparison between diabetic and non-diabetic rats before VMH lesion shows insulin deficiency in the diabetic rats (Fig. 1). Values of the mean incremental insulin area, the mean incremental glucose area and the insulinogenic index were respectively: non-diabetic females: $40 \pm 5 \mathrm{mU} \cdot \mathrm{min} \cdot 1^{-1}$, $70 \pm 5 \mathrm{mmol} \cdot \mathrm{min} \cdot \mathrm{l}^{-1}, 0.64 \pm 0.08, \mathrm{n}=21$; and diabetic females $17 \pm 2 \mathrm{mU} \cdot \min \cdot 1^{-1}, \quad 60 \pm 7 \mathrm{mmol} \cdot \mathrm{min} \cdot 1^{-1}$, $0.36 \pm 0.06, \mathrm{n}=19$.

Table 1 shows the basic characteristics of diabetic and normal females before and 2 months after VMH lesion. During this 2-month period, in a control group of eight non-diabetic females without VMH lesions, the mean daily body-weight gain was $0.17 \pm 0.05 \mathrm{~g}$. In both diabetic and non-diabetic rats with VMH lesions body weight gain was similarly increased $(1.58 \pm 0.32$ and $1.50 \pm 0.21 \mathrm{~g}$, respectively), reaching a value ninefold higher than in the controls. The presence of a VMH lesion did not significantly affect the basal plasma glucose levels in either the normal or the diabetic animals. However in both groups basal plasma insulin was significantly greater after making the lesions than before, the increase being similar in the two groups (by a factor of 2.3 in the diabetic and 2.7 in the non-diabetic animals).

Effect of hypothalamic obesity on the evolution of non-insulin-dependent diabetes: Plasma glucose and insulin levels following intravenous glucose were determined 2 months after the lesion in both diabetic and nondiabetic females (Fig.1). In the non-diabetic females, VMH lesions did not result in any significant change in the mean incremental glucose area calculated within 90 
Table 1. Effect of bilateral ventromedial hypothalamic (VMH) lesion on basal plasma glucose and insulin in diabetic and control rats. Non-insulin-dependent diabetes was induced in the adult rats by neonatal administration of streptozotocin $(100 \mathrm{mg} / \mathrm{kg})$

\begin{tabular}{|c|c|c|c|c|c|c|c|}
\hline & \multicolumn{3}{|c|}{ Before VMH lesion } & \multicolumn{4}{|c|}{2 months after VMH lesion } \\
\hline $\begin{array}{l}\text { Control rats } \\
\text { with VMH lesion }\end{array}$ & $\begin{array}{l}193 \pm 10 \\
(21)\end{array}$ & $\begin{array}{l}7.1 \pm 0.2 \\
(21)\end{array}$ & $\begin{array}{l}43 \pm 4 \\
(21)\end{array}$ & $\begin{array}{l}304 \pm 15 \\
(16)\end{array}$ & $\begin{array}{l}99 \pm 20 \\
(16)\end{array}$ & $\begin{array}{l}7.6 \pm 0.1 \\
(16)\end{array}$ & $\begin{array}{l}115 \pm 21 \\
(16)\end{array}$ \\
\hline
\end{tabular}

Values are expressed as mean $\pm \mathrm{SEM}$; numbers of observations in parentheses. ${ }^{a} p<0.01$ compared with values in controls with VMH-lesion; ${ }^{\mathrm{b}} p<0.001$ compared with values in controls with VMH-lesion

Table 2. Long-term study of the evolution of non-insulin-dependent diabetes in four obese female rats

\begin{tabular}{|c|c|c|c|c|c|c|}
\hline & $\begin{array}{l}\text { Body } \\
\text { weight } \\
\text { (g) }\end{array}$ & $\begin{array}{l}\text { Plasma } \\
\text { glucose } \\
(\mathrm{mmol} / 1)\end{array}$ & $\begin{array}{l}\text { Plasma } \\
\text { insulin } \\
(\mathrm{mU} / \mathrm{l})\end{array}$ & $\begin{array}{l}\text { Incremental } \\
\text { glucose area } \\
\left(\mathrm{mmol} \cdot \mathrm{min} \cdot 1^{-1}\right)\end{array}$ & $\begin{array}{l}\text { Incremental } \\
\text { insulin area } \\
\left(\mathrm{mU} \cdot \mathrm{min} \cdot \mathrm{l}^{-1}\right)\end{array}$ & $\begin{array}{l}\text { Insulinogenic } \\
\text { index }\end{array}$ \\
\hline 9 months after VMH-lesion & $334 \pm 24$ & $9.8 \pm 0.3^{\mathrm{a}}$ & $79 \pm 19$ & $123 \pm 24$ & $54 \pm 10$ & $0.505 \pm 0.164^{b}$ \\
\hline
\end{tabular}

Values are expressed as mean \pm SEM. a $p<0.05$ compared with value in 2-month old rats; b $p<0.02$ compared with value in 2-month old rats. The mean incremental glucose area, the mean incremental insulin area and the insulinogenic index were calculated from values obtained during a $90-\mathrm{min}$ intravenous glucose tolerance test $(2.8 \mathrm{mmol} / \mathrm{kg})$ in the obese diabetic rats

Table 3. Basal characteristics in 3-month old female Zucker rats, lean or obese, with or without STZ treatment at birth

\begin{tabular}{|c|c|c|c|c|c|}
\hline 3 month-old Zucker rats & Genotype & $\begin{array}{l}\text { Body } \\
\text { weight } \\
\text { (g) }\end{array}$ & $\begin{array}{l}\text { Plasma } \\
\text { glucose } \\
(\mathrm{mmol} / \mathrm{l})\end{array}$ & $\begin{array}{l}\text { Plasma } \\
\text { insulin } \\
(\mathrm{mU} / \mathrm{l})\end{array}$ & $\begin{array}{l}\text { Pancreatic } \\
\text { insulin } \\
(\mathrm{m} U / \mathrm{mg})\end{array}$ \\
\hline Lean $+\mathrm{STZ}(100 \mathrm{mg} / \mathrm{kg})$ & $F a f a$ & $\begin{array}{c}155 \pm 9 \\
(9)\end{array}$ & $\begin{array}{l}9.5 \pm 0.5^{b} \\
(8)\end{array}$ & $\begin{array}{l}15 \pm 5 \\
(8)\end{array}$ & $\begin{array}{l}1.51 \pm 0.20^{\mathrm{a}} \\
(9)\end{array}$ \\
\hline Obese $+\mathrm{STZ}(100 \mathrm{mg} / \mathrm{kg})$ & $f a / f a$ & $\begin{array}{l}229 \pm 22^{c} \\
(5)\end{array}$ & $\begin{array}{l}7.6 \pm 0.9 \\
(5)\end{array}$ & $\begin{array}{l}89 \pm 34 \\
(5)\end{array}$ & $\begin{array}{l}2.34 \pm 0.52^{\mathrm{a}} \\
(5)\end{array}$ \\
\hline
\end{tabular}

Values are expressed as mean \pm SEM; number of observations in parentheses.

${ }^{\mathrm{a}} p<0.01,{ }^{\mathrm{b}} p<0.001$ when values of STZ-treated rats are different from those of corresponding non-treated rats; ${ }^{\mathrm{c}} p<0.02, \quad{ }^{\mathrm{d}} p<0.01$, e $p<0.001$ when values of obese rats are different from those of corresponding lean rats

$\min$ of the test $\left(77 \pm 7 \mathrm{mmol} \cdot \min \cdot 1^{-1}, n=16\right)$. By contrast, the increment of plasma insulin level in response to glucose load at this time was more pronounced (Fig. 1). The mean incremental insulin area $(103 \pm 22$ $\mathrm{mU} \cdot \min \cdot 1^{-1}, n=16$ ) was increased by a factor of 2.6 $(p<0.01)$ and the insulinogenic index $(1.43 \pm 0.25$, $n=16)$ showed a 2.2 -fold increment $(p<0.01)$.

A longitudinal study of body weight and glycosuria was performed in 16 diabetic females with VMH lesions. Three exhibited glycosuria, which was transient in two females and permanent in one. In these females the onset of overt diabetes followed a dynamic phase of obesity which lasted about 2 months. By contrast, glycosuria was never observed in diabetic females without lesions, nor in non-diabetic females with lesions. In the remaining 13 females, 2 months after the lesion, plasma glucose levels 5 and $15 \mathrm{~min}$ after a glucose load were significantly increased $(p<0.001)$ compared with the pre-lesion values (Fig. 1). The corresponding increment in plasma insulin level (Fig. 1), the incremental insulin area $\left(85 \pm 19 \mathrm{mU} \cdot \min \cdot 1^{-1} n=13\right)$ and the insulinogenic index $(0.97 \pm 0.25, n=13)$ were significantly greater than in the pre-lesion test. Nine months after the VMH lesion, the diabetic females exhibited a statistically significant increase in basal plasma glucose and a significant decrease in insulinogenic index, compared with the 2-month post-lesion values (Table 2). This indicates that both glucose tolerance and insulin secretory re- 

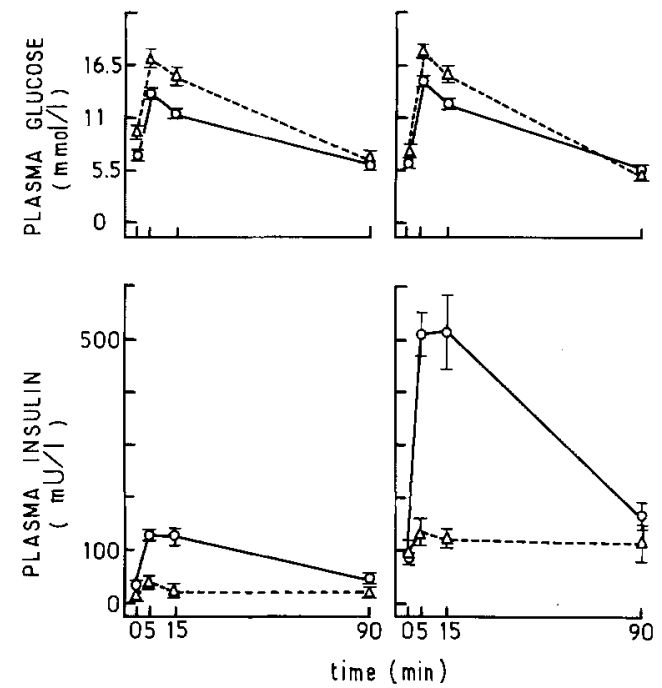

Fig. 2. Effect of genetic obesity on glucose tolerance and plasma insulin response to glucose $(2.8 \mathrm{mmol} / \mathrm{kg}$, IV) in control female Zucker rats $\left(O_{-}-O_{)}\right)$and female Zucker rats treated with $S T Z(100 \mathrm{mg} / \mathrm{kg})$ at birth $(\triangle \cdots \triangle)$. The animals were tested at 3 months. Left-hand panels concern lean $\mathrm{Fa} / \mathrm{fa}$ rats, right-hand panels obese $f a / f a$ rats. Each point is mean \pm SEM of five to eight observations in each group

sponse of the diabetic females with lesions tended to deteriorate during this period (8-15 months of age), although they never became glycosuric. This contrasts with the lack of deterioration of glucose tolerance and insulin secretory response in the diabetic females without lesions observed during the same period (unpublished data).

\section{Non-Insulin-Dependent Diabetes in the Zucker Rats}

Effect of STZ injected at birth in the lean Fa/fa Zucker rats: Data obtained in adult lean $\mathrm{Fa} / \mathrm{fa}$ Zucker rats (Table 3 and Fig. 2) clearly indicate that STZ, when injected on the day of birth at the dose of $100 \mathrm{mg} / \mathrm{kg}$, has the same long-term diabetogenic effect in these animals as in the Wistar strain (Table 1 and Fig. 1).

Effect of STZ injected at birth on the development of obesity and on basal plasma glucose and insulin levels in fa/fa rats: In this study the newborn rats were all bred by crossing $f a / f a$ obese males with known $\mathrm{Fa} / \mathrm{fa}$ females. Obese animals were obtained with a $45 \%$ yield $(27 / 60)$ in the non-treated newborns and a $56 \%$ yield $(19 / 34)$ in the STZ-treated newborns. Therefore STZ treatment at birth did not prevent the development of obesity in the $f a / f a$ Zucker rat. As shown in Table 3, 3month-old diabetic obese Zucker females exhibited the same body weight excess as the non-diabetic obese females. Basal plasma glucose levels in the diabetic obese rats were not significantly different from those in the obese controls, but were significantly decreased compared with the level in the diabetic lean females. Basal plasma insulin levels in both obese groups were similar, and they were increased significantly when compared with the levels in the lean animals. Pancreatic insulin stores were significantly higher in the diabetic obese than in diabetic lean animals, although they were significantly lower than those of the obese controls.

Effect of obesity on non-insulin-dependent diabetes in the fa/fa Zucker rat: Plasma glucose and insulin levels following an intraverious glucose injection were determined in 3-month old Zucker rats either lean or obese and with or without diabetes (Fig. 2).

In the obese control females, post-injection plasma glucose levels were not significantly different from those of the lean controls. However, the increment of plasma insulin level after glucose load was 4.6-fold higher $(p<0.001)$ in the obese controls $(171 \pm 27 \mathrm{mU}$. $\left.\min \cdot 1^{-1}, n=7\right)$ than in the lean controls $(36 \pm 6 \mathrm{mU}$. $\left.\min \cdot 1^{-1}, n=7\right)$. The insulinogenic index was fourfold higher $(p<0.01)$ in the obese females $(2.61 \pm 0.54, n=7)$ than in the lean females $(0.66 \pm 0.11, n=7)$. Seven of the 20 STZ-treated obese Zucker rats showed short periods of glycosuria in adulthood. This late-appearing glycosuria, coexistent with the development of obesity, was clearly separated from the neonatal glycosuric period characteristic of the acute neonatal diabetes (from day 2-10 after birth). In neither lean diabetic rats nor nondiabetic obese rats was glycosuria observed. In the obese diabetic females, post-injection plasma glucose levels were not significantly different from those in lean diabetic animals. The increment in plasma insulin levels after the glucose load was greater in the obese than in the lean diabetic rats (Fig. 2) and the mean incremental insulin area was 3.5 times higher $(p<0.01)$ in the obese diabetics $\left(35 \pm 6 \mathrm{mU} \cdot \min \cdot 1^{-1}, n=5\right)$ than in the lean diabetics $\left(10 \pm 1 \mathrm{mU} \cdot \min \cdot 1^{-1}, n=8\right)$. Compared with that in the lean diabetic rats $\left(0.20 \pm 0.03 \mathrm{mU} \cdot \min \cdot 1^{-1}\right.$, $n=8)$, the insulinogenic index in obese diabetic rats $(0.42 \pm 0.09, n=5)$ was increased by $2.1(p<0.05)$, but remained six times lower than in the non-diabetic obese rats $(2.61 \pm 0.54, n=7)$.

\section{Discussion}

These observations indicate that a state of non-insulindependent diabetes does not prevent the development of obesity. The finding that obesity may develop after VMH lesions, in spite of diabetes, is different from previous reports in the rat which showed that overt diabetes following acute destruction of pancreatic B cells by alloxan [5] or STZ [15] prevented VMH obesity. Similarly, Young and Liu [16] previously observed that when subtotal pancreatectomy was performed in rats, weight gain did not occur after VMH lesion. Nevertheless, Brobeck et al. [2] reported that partial pancreatectomy did not prevent the development of obesity following hypothalamic damage. In this last experiment, it was presumed that the remaining pancreas was able to provide sufficient insulin for the development of obesity in such 
animals. In none of the above mentioned studies was insulin secretion measured both before and after hypothalamic lesions. In addition, in most of these experiments, the diabetic animals were given insulin replacement therapy before and after making the $\mathrm{VMH}$ lesion.

This study shows that the rats with non-insulindependent diabetes increase glucose-induced insulin release in vivo during the development of obesity, whether experimentally induced or genetically determined. In the diabetic rats with VMH lesions, the insulin response to glucose is so dramatically increased that it is no longer significantly different from that in nondiabetic rats with lesions. Thus the diabetic rats are able to increase their insulin secretory capacity when obesity develops, but this adjustment is transient and the islets seem unable to ensure a long lasting adaptation to the insulin requirement.

Likewise in the diabetic $f a / f a$ Zucker rat, the insulin response to glucose is increased when the animals become obese, although this increase remains significantly smaller than that observed in the obese Zucker rats without diabetes. It should be pointed out that a substantial degree of hyperinsulinaemia is not essential for the development of obesity in $f a / f a$ Zucker rats as suggested by Stolz and Martin [14]. These authors recently showed that obese rats were still gaining more lipid than the lean rats in spite of the equalization of available insulin. This ability of the endocrine pancreas in the rats with non-insulin-dependent diabetes to respond somehow to a chronic stimulator, such as obesity, has also been shown in pregnant female rats with non-insulin-dependent diabetes [11].

Although glucose-induced insulin secretion is increased in diabetic rats becoming obese, these animals clearly do not ameliorate their glucose tolerance, suggesting the development of a state of insulin resistance related to obesity. Indeed, in some of these animals overt diabetes with permanent or transient glycosuria and basal hyperglycaemia developed. This was noted in almost one-third of the diabetic obese rats. Thus obesity may be looked upon as a contributing factor in the development of diabetes in insulin-deficient rats as well as in insulin-deficient man [3]. In conclusion, the obese rat with mild diabetes appears to be a suitable laboratory model for the study of the relationship between obesity and diabetes.

Acknowledgements. We are grateful to Dr. G. Rosselin (INSERM Unité 55) for the gift of monoiodinated insulin and to Dr. J.P. Paturaud (Upjohn, Paris, France) for the gift of streptozotocin. This work was supported by the Institut National de la Santé et de la Recherche Médicale (INSERM) (CRL No 79-14837).

\section{References}

1. Bennett PH, Le Compte PM, Miller M, Rushforth NB (1976) Epidemiological studies of diabetes in the Pima Indians. Recent Prog Horm Res 32: 333-376

2. Brobeck Jr, Tepperman J, Long CN (1943) Experimental hypothalamic hyperphagia in the albino rat. Yale J Biol Med 15: 831-853

3. Cerasi E, Luft R (1967) 'What is inherited-what is added' hypothesis for the pathogenesis of diabetes mellitus. Diabetes 16: 615-627

4. Freychet P, Roth J, Neville DM (1971) Monoiodo-insulin: demonstration of biological activity and binding to fat cells and liver membranes. Biochem Biophys Res Commun 43: 400-408

5. Friedman MI (1972) Effects of alloxan diabetes on hypothalamic hyperphagia and obesity. Am J Physiol 222: 174-178

6. Gerritsen GC, Blanks MC (1970) Preliminary studies on food and water consumption of prediabetic Chinese hamsters. Diabetologia 6: $177-179$

7. Gerritsen GC, Blanks MC, Miller RL, Dulin WE (1974) Effect of diet limitation on the development of diabetes in prediabetic Chinese hamsters. Diabetologia 10: 559-565

8. Hemmes RB, Hubsch S, Pack HM (1978) High dosage of testosterone propionate increases litter production of the genetically obese-male Zucker rats. Proc Soc Exp Biol Med 159: 424-427

9. Portha B, Levacher C, Picon L, Rosselin G (1974) Diabetogenic effect of streptozotocin in the rat during the perinatal period. Diabetes 23:889-895

10. Portha B, Picon L, Rosselin G (1979) Chemical diabetes in the adult rat as the spontaneous evolution of neonatal diabetes. Diabetologia 17: 371-377

11. Portha B, Triadou N, Picon L, Rosselin G (1980) Experimental chemical diabetes in the rat: effects of dietary carbohydrate content and gestation. Diabetologia 19:308 A

12. Rosselin G, Assan R, Yalow RS, Berson SA (1966) Separation of antibody-bound and unbound peptide hormones labelled with iodine 131 by talcum powder and precipitated silica. Nature 212: 355-357

13. Seltzer HS, Allen EW, Herron AL, Brennan MT (1967) Insulin secretion in response to glycemic stimulus: relation of delayed initial release to carbohydrate intolerance in mild diabetes mellitus. $\mathrm{J}$ Clin Invest 46: 323-325

14. Stolz DJ, Martin RJ (1982) Role of insulin in food intake, weight gain and lipid deposition in the Zucker obese rat. J Nutr 112: 997-1002

15. York DA, Bray GA (1972) Dependence of hypothalamic obesity on insulin, the pituitary and the adrenal gland. Endocrinology 90 : 885-894

16. Young TK, Liu AC (1965) Hyperphagia, insulin and obesity. Chinese J Physiol 19:247-253

17. Zucker TF (1962) Hereditary obesity in the rat associated with high serum fat and cholesterol. Proc Soc Exp Biol Med 110: 165-171

Received: 20 September 1982

and in revised form: 5 April 1983

Dr. Bernard Portha

Laboratoire de Physiologie du Développement

Tour 23-1 er étage

Université Paris VII

2 Place Jussieu

F-75251 Paris Cedex 05

France 